\title{
Distribution of Macrolide-Lincosamide- Streptogramin B antibiotics resistance genes in clinical isolates of Staphylococci
}

Dharma Nagarkoti

Tribhuvan University - Trichandra Multiple Campus

Krishna Prajapati

B \& B Hospital

Ajay Narayan Sharma

Intrepid Nepal

Arrogya Gyawali

Intrepid Nepal

Sarita Manandhar ( $\nabla$ sarita111@gmail.com )

Tribhuvan University - Trichandra Multiple Campus

Research

Keywords: Staphylococci, MLSB, D test, erm gene, msr gene

Posted Date: December 27th, 2019

DOI: https://doi.org/10.21203/rs.2.19686/v1

License: (9) This work is licensed under a Creative Commons Attribution 4.0 International License.

Read Full License 


\section{Abstract}

\section{Background}

Staphylococci are the most commonly isolated pathogen from clinical specimen. These isolates are posing threat due to increasing trend of antimicrobial resistance particularly methicillin. Macrolidelincosamide streptogramin B family of antibiotics is commonly used to treat such infections. This study was aimed to detect the prevalence of inducible clindamycin resistance and observation of erm and msr genes among Staphylococci isolated from tertiary care hospital of Nepal.

Methods

Staphylococci from different clinical specimen were identified and antibiotic susceptibility profile were determined following Kirby Bauer disc diffusion method. The double disc diffusion or D-zone test as outlined in CLSI document M100-S24 was performed to examine inducible clindamycin resistance isolates. Multiplex PCR was performed for detection of erm and msr gene in isolates using specific primers for ermA , ermB, ermC, msrA and msrB genes.

Results

Of the 60 Staphylococci isolates, 39 (65\%) were Staphylococcus aureus ( S. aureus ) and 21 (35\%) were coagulase negative Staphylococci (CNS) with $25(64 \%)$ and $15(71 \%)$ representing methicillin resistant S. aureus and CNS respectively. Constitutive and inducible MLS B phenotype was observed among 24 (40\%) and $14(23 \%)$ isolates respectively by $D$ test. The most prevalent resistant gene was ermC gene (37\%) followed by msr B (12\%), erm B (10\%) and msr A (10\%). None of the isolates were found to possess erm A gene.

\section{Conclusions}

The resistant genes were detected more among CNS than S. aureus. The presence of constitutive and inducible MLS B as well as resistant genes among Staphylococci necessitates detection of such isolates to minimize treatment failure. The presence of resistant characteristic varies with hospital settings, geographical locations, patients' demography etc. The result from this study may help elucidate the predominant resistant characteristics in clinical Staphylococci isolated from tertiary care hospital of Nepal.

\section{Background}

Both Staphylococcus aureus (S. aureus) and coagulase negative Staphylococci (CNS) are responsible for various diseases ranging from mild skin soft tissue infections to life threatening conditions as endocarditis, pneumonia, sepsis [1, 2]. Staphylococci are an emerging problem due to their increasing resistance to several antibiotics [3]. Marolides, lincosamides and streptogramin $B\left(M_{B} S_{B}\right)$ antibiotics are now preferred in the treatment of staphylococcal infections due to rise in methicillin resistance, as an 
alternative to patient allergic to penicillin and for excellent pharmacokinetic properties. Although $M L S_{B}$ antibiotics are structurally distinct, the mode of action is similar because they inhibit protein synthesis by binding to the 50 S subunit (23S rRNA) of bacterial ribosome. However, widespread use of $M_{L} S_{B}$ antibiotics has caused an increase in the number of strains resistant to it $[4,5,6,7]$.

Three mechanisms of resistance to $\mathrm{MLS}_{\mathrm{B}}$ antibiotics have been described. The active efflux mechanism encoded by msr gene making isolates resistant to erythromycin and sensitive to clindamycin both in vitro and in vivo but typically resistant to clindamycin during therapy. The enzymatic drug inactivation mediated by inuA. The inuA gene encodes lincosamide 0-nucleotidyltransferase which only inactivates lincosamides. The most common resistance mechanism is target site modification by methylation or mutation in the 23S rRNA, mediated by erm genes (ermA, ermB, ermC and ermF). The predominant genes responsible for resistance to $M L S_{B}$ antibiotics are ermA and ermC. These are expressed either constitutively $\left(\mathrm{CMLS}_{\mathrm{B}}\right)$ or inducibly $\left(\mathrm{iMLS}_{\mathrm{B}}\right)[6,8]$.

In routine laboratory, detecting inducible clindamycin resistance is difficult, as in vitro they appear resistant to erythromycin and sensitive to clindamycin when placed adjacent to each other. In such cases, in vivo treatment of patients with clindamycin can lead to emergence of resistant mutants to $c M L S_{B}$ from $\mathrm{iMLS}_{\mathrm{B}}$ causing treatment failure $[9,10]$. Clinical and Laboratory Standard Institute (CLSI) developed a reliable phenotypic method, the double disk diffusion test (D-test) to screen iMLS ${ }_{B}$ resistant isolates $[9$, $11,12,13]$.

In Nepal, reports on inducible clindamycin resistance among clinical Staphylococci are limited. This study was conducted to determine the frequency of inducible clindamycin resistance phenotypically using $D$ test and genotypically using PCR to confirm the presence of erm and msr genes.

\section{Methods}

Collection and identification of isolates

A total of 312 Staphylococci were isolated from various clinical specimens like pus, wound swab, blood, urine, sputum, tissues and various tips (catheter tip, suction tip, drain tip, double $J$ (DJ) stent, tracheal tip, endotracheal tip). The isolates were identified as staphylococcal strain on the basis of colony morphology on Nutrient agar, Blood Agar and Mannitol Salt, Gram's stain, and different biochemical tests. The slide and tube coagulase test were used to differentiate $S$. aureus and CNS [14].

Antimicrobial susceptibility test

The antimicrobial susceptibility test (AST) of all isolates was performed by modified Kirby Bauer disc diffusion technique [13]. We used different antibiotics based on different mode of action and clinical relevance. The antibiotic discs (HiMedia, India) used were penicillin-G, cefoxitin, ciprofloxacin, clindamycin, chloramphenicol, erythromycin, gentamicin, ofloxacin, azithromycin and linezolid. Strains showing resistance to three or more than three different classes of antibiotics were considered multidrug 
resistant. Cefoxitin disc was used to detect methicillin resistance. S. aureus ATCC 25923 was used as control strain in each AST assay along with the test strains [13].

Screening of inducible clindamycin resistance

The double disc diffusion or D-zone test as outlined in CLSI document M100-S24 (2015) was performed to examine whether the erythromycin resistant isolates expressed inducible clindamycin resistance. Briefly, the bacterial isolates were diluted to $0.5 \mathrm{McFarland}$ standard and spread over Mueller Hinton agar (MHA) plate, on which erythromycin $(15 \mu \mathrm{g})$ disc and clindamycin $(2 \mu \mathrm{g})$ disc were placed $15-26 \mathrm{~mm}$ edge to edge apart and incubated at $35^{\circ} \mathrm{C}$ for $16-18$ hours in aerobic condition.

Clindamycin resistance was detected as:

- $\mathrm{iMLS}_{\mathrm{B}}$ phenotype: resistant to erythromycin (zone size $\leq 13 \mathrm{~mm}$ ) while sensitive to clindamycin (zone size $\geq 21 \mathrm{~mm}$ ) with a D-shaped zone of inhibition

- $\mathrm{CMLS}_{\mathrm{B}}$ phenotype: resistant to both erythromycin and clindamycin (zone size $\leq 14 \mathrm{~mm}$ )

- MS phenotype: resistant to erythromycin and susceptible to clindamycin without D-zone [13].

Multiplex polymerase chain reaction for erm and msr gene

The genomic DNA was extracted using the DNA extraction Kit (Thermo Fischer) according to the manufacturer's protocol.

Multiplex PCR was performed for detection of erm and msr gene in isolates using specific primers for ermA, ermB, ermC, msrA and msrB genes (Table 1). Each PCR was performed in a final volume of $15 \mu \mathrm{L}$ consisting of $3 \mu \mathrm{L}$ of master mix, $0.3 \mu \mathrm{L}$ of each ermA, ermB, ermC, msrA, and msrB forward and reverse primers respectively, $10.4 \mu \mathrm{L}$ RNase free water and $1 \mu \mathrm{L}$ of extracted DNA. DNA was amplified on a MJ Research PTC-225 Gradient Thermal Cycler, and DNA amplification was carried out with following parameters: preheating at $94^{\circ} \mathrm{C}$ for $10 \mathrm{~min}, 35$ cycles of amplification with denaturation at $94^{\circ} \mathrm{C}$ for $30 \mathrm{~s}$, annealing at $53^{\circ} \mathrm{C}$ for $30 \mathrm{~s}$, and extension at $72{ }^{\circ} \mathrm{C}$ for $60 \mathrm{~s}$, followed by a termination at $72{ }^{\circ} \mathrm{C}$ for $10 \mathrm{~min}$. The PCR product was analyzed in $2 \%$ agarose gel stained with ethidium bromide dye using standard molecular weight markers (100 kb DNA ladder; Solis Biodyne, Estonia). 
Table 1

Primers used in the study $[15,16]$

\begin{tabular}{|c|c|c|}
\hline Target gene & Primer sequence & bp \\
\hline \multirow[t]{2}{*}{ ermA } & 5'-GTTCAAGAACAATCAATACAGAG-3' & 421 \\
\hline & 5'-GGATCAGGAAAAGGACATTTTAC-3' & \\
\hline \multirow[t]{2}{*}{ ermB } & 5'-CGTTTACGAAATTGGAACAGGTAAAGGGC-3' & 359 \\
\hline & 5'-GAATCGAGACTTGAGTGTGC-3' & \\
\hline \multirow[t]{2}{*}{ ermC } & 5'-GCTAATATTGTTTAAATCGTCAATTCC-3' & 572 \\
\hline & 5'-GGATCAGGAAAAGGACATTTTAC-3' & \\
\hline \multirow[t]{2}{*}{ msra } & 5'-GGCACAATAAGAGTGTTTAAAGG-3' & 940 \\
\hline & 5'-AAGTTATATCATGAATAGATTGTCCTGTT-3' & \\
\hline \multirow[t]{2}{*}{ msrB } & 5'-TATGATATCCATAATAATTATCCAATC-3' & 595 \\
\hline & 5'-AAGTTATATCATGAATAGATTGTCCTGTT-3' & \\
\hline
\end{tabular}

\section{Results}

Among 312 Staphylococcal isolates, 60 isolates were found to be erythromycin resistant comprising of 39 (65\%) S. aureus and 21 (35\%) CNS. Staphylococci were isolated more frequently from wound/pus (46, $77 \%)$ followed by urine $(9,15 \%)$, blood $(3,5 \%)$ and tips $(2,3 \%)$.

Antibiotic susceptibility testing of 10 clinically relevant antibiotics was performed for 60 erythromycin resistant isolates. The isolates were found resistant to Fluoroquinolone group of antibiotics, $70 \%$ isolates showing resistant to ofloxacin and ciprofloxacin. However, most of the isolates were susceptible to linezolid (88.3\%). Similarly, 56\% Staphylococci were resistant to methicillin representing $42 \%$ S. aureus and $25 \%$ CNS (Table 2). 
Table 2

Antibiotic susceptibility pattern of isolates

\begin{tabular}{|lllllll|}
\hline \multirow{2}{*}{ Class } & Antibiotics & \multirow{2}{*}{ Potency } & \multicolumn{2}{l}{ Resistant } & \multicolumn{2}{l|}{ Sensitive } \\
\cline { 4 - 7 } & & & N & $\%$ & N & $\%$ \\
\hline Aminoglycosides & Amikacin & $30 \mathrm{mcg}$ & 31 & 51.7 & 29 & 48.3 \\
& Gentamycin & $10 \mathrm{mcg}$ & 31 & 51.7 & 29 & 48.3 \\
\hline Cephalosporins & Cefoxitin & $30 \mathrm{mcg}$ & 40 & 55.7 & 20 & 33.3 \\
\hline Fluoroquinolones & Ciprofloxacin & $5 \mathrm{mcg}$ & 42 & 70 & 18 & 30 \\
\hline & Ofloxacin & $5 \mathrm{mcg}$ & 42 & 70 & 18 & 30 \\
\hline Lincosamides & Clindamycin & $2 \mathrm{mcg}$ & 38 & 63.3 & 22 & 36.7 \\
\hline Macrolides & Erythromycin & $15 \mathrm{mcg}$ & 60 & 100 & - & - \\
\hline & Azithromycin & $15 \mathrm{mcg}$ & 41 & 68.3 & 19 & 31.7 \\
\hline Oxazolidones & Linezolid & $30 \mathrm{mcg}$ & 7 & 11.7 & 53 & 88.3 \\
\hline Others & Chloramphenicol & $30 \mathrm{mcg}$ & 15 & 25 & 45 & 75 \\
\hline
\end{tabular}

In this study, almost all isolates of Staphylococci presented $\mathrm{MLS}_{\mathrm{B}}$ resistant phenotypes. In fact, $\mathrm{cMLS} \mathrm{B}_{\mathrm{B}}$ resistant phenotype was the most common and highest $(40 \%)$ followed by $\mathrm{MS}_{\mathrm{B}}(37 \%)$ and $\mathrm{iMLS} \mathrm{B}_{\mathrm{B}}(23 \%)$ phenotypes. In this study, 8 (13.3\%) S. aureus isolates were $\mathrm{iMLS}_{\mathrm{B}}, 12(20 \%) \mathrm{CMLS}_{\mathrm{B}}$ and $19(31.7 \%)$ were of MS phenotypes (Table 3 ).

Table 3

Susceptibility to erythromycin and clindamycin among Staphylococci isolates

\begin{tabular}{|c|c|c|c|c|c|c|c|c|c|c|}
\hline \multirow[t]{2}{*}{ Phenotypes } & \multicolumn{2}{|c|}{ MRSA } & \multicolumn{2}{|c|}{ MSSA } & \multicolumn{2}{|c|}{ MRCNS } & \multicolumn{2}{|c|}{ MSCNS } & \multicolumn{2}{|c|}{ Total } \\
\hline & $\mathbf{N}$ & $\%$ & $\mathbf{N}$ & $\%$ & $\mathbf{N}$ & $\%$ & $\mathbf{N}$ & $\%$ & $\mathbf{N}$ & $\%$ \\
\hline E-R, CD-R (constitutive MLS ${ }_{B}$ ) & 3 & 12 & 5 & 35.7 & 12 & 80 & 4 & 66.7 & 24 & 40 \\
\hline $\begin{array}{l}\text { E-R, CD-S (inducible } \mathrm{MLS}_{\mathrm{B}} \text {, D- } \\
\text { positive) }\end{array}$ & 11 & 44 & 1 & 7.2 & 2 & 13.3 & - & - & 14 & 23.3 \\
\hline E-R, CD-S (MS, D-negative) & 11 & 44 & 8 & 57.1 & 1 & 6.7 & 2 & 33.3 & 22 & 36.7 \\
\hline
\end{tabular}


According our findings, the ermC gene was the most prevalent among Staphylococci isolates $(22,37 \%)$ followed by ermB among $6(10 \%)$ isolates while ermA gene was not detected. Among $39 \mathrm{~S}$. aureus, ermC and ermB was detected in $14(36 \%)$ and $2(5 \%)$ respectively. Similary, among 21 CNS isolates, the presence of ermC and ermB was observed in $8(38 \%)$ and $4(19 \%)$ respectively (Table 4, Fig. 1, Fig. 2). In this study, $6(10 \%)$ isolates were detected with the presence of msrA and $7(12 \%)$ with msrB genes.

Similarly, msrA and msrB were detected among 1 (2.6\%) and 2 (5.1\%) S. aureus whereas both msrA and msrB genes were detected in $5(23.8 \%)$ CNS isolates (Table 4$)$.

Table 4

Distribution of resistant genes among the isolates

\begin{tabular}{|c|c|c|c|c|c|c|c|c|}
\hline \multirow[t]{3}{*}{ Resistant genotype } & \multicolumn{6}{|c|}{ No. of isolates with phenotype } & \multirow{2}{*}{\multicolumn{2}{|c|}{ Total }} \\
\hline & $\mathrm{CMLS}_{\mathrm{B}}$ & & $\mathrm{iMLS}_{\mathrm{B}}$ & & $\mathrm{MLS}_{\mathrm{B}}$ & & & \\
\hline & $\begin{array}{l}\text { S. } \\
\text { aureus }\end{array}$ & CNS & $\begin{array}{l}\text { S. } \\
\text { aureus }\end{array}$ & CNS & $\begin{array}{l}\text { S. } \\
\text { aureus }\end{array}$ & CNS & $\begin{array}{l}\text { S. } \\
\text { aureus }\end{array}$ & CNS \\
\hline ermA & 0 & 0 & 0 & 0 & 0 & 0 & 0 & 0 \\
\hline ermB & 0 & 3 & 1 & 1 & 1 & 0 & 2 & 4 \\
\hline ermC & 3 & 5 & 10 & 2 & 1 & 1 & 14 & 8 \\
\hline msra & 1 & 5 & 0 & 0 & 0 & 0 & 1 & 5 \\
\hline $\mathrm{msrB}$ & 1 & 5 & 0 & 0 & 1 & 0 & 2 & 5 \\
\hline ermB + ermC & 0 & 1 & 1 & 1 & 0 & 0 & 1 & 2 \\
\hline$e r m B+m s r A+m s r B$ & 0 & 1 & 0 & 0 & 0 & 0 & 0 & 1 \\
\hline $\begin{array}{l}\text { ermB }+ \text { ermB }+ \text { msrA }+ \\
m s r B\end{array}$ & 0 & 1 & 0 & 0 & 0 & 0 & 0 & 1 \\
\hline$m s r A+m s r B$ & 1 & 3 & 0 & 0 & 0 & 0 & 1 & 3 \\
\hline No gene & 4 & 7 & 2 & 0 & 16 & 2 & 22 & 9 \\
\hline
\end{tabular}

The erm genes were detected in 5 isolates showing $\mathrm{CMLS}_{\mathrm{B}}, 12$ isolates showing $\mathrm{iMLS}_{\mathrm{B}}$ and 2 isolates with MS phenotype. Similarly, ermB gene was detected 3 isolates showing $\mathrm{CMLS}_{B}, 2$ isolates showing $\mathrm{iMLS}_{\mathrm{B}}$ and a single isolate with MS phenotype. None of the isolates with $M L S_{B}$ resistance were detected with ermA gene (Table 4).

\section{Discussion}

Staphylococci are responsible for a wide spectrum of diseases. Currently, the organism is posing a global threat due to high rate of antibiotic resistance. Antibiotic susceptibility testing of 10 clinically relevant 
antibiotics was performed for 60 erythromycin resistant isolates. The isolates were found resistant to Fluoroquinolone group of antibiotics, $70 \%$ isolates showing resistant to ofloxacin and ciprofloxacin. However, most of the isolates (88.3\%) were susceptible to linezolid. Methicillin resistance was observed among $56 \%$ Staphylococci with $42 \%$ S. aureus and $25 \%$ CNS. This result is in accordance with the findings disseminated by other studies done in various regions of Nepal $[17,18]$ and of the world $[11,19$, $20,21]$. A marked variation has been observed in methicillin resistance isolated among different geographical condition as well as among hospitals of same country. In Nepal, a relatively lower rate of MRSA and MRCNS (18\% \& 9\%) was reported by Thapa and Sapkota [18]. Another report, however, showed alarmingly high MRSA prevalence of $75.5 \%$ and $69 \%[22,23]$. Inappropriate use of antibiotics, improper infection control procedure in hospitals, increased use of medical implants may contribute to emerging methicillin resistant isolates.

Increasing frequency of MRSA and MRCNS infection and changing pattern in antibiotic resistance have sparked renewed interest in the use of $\mathrm{MLS}_{\mathrm{B}}$ antibiotic. Particularly, clindamycin has become an excellent drug for Staphylococcal infection as an alternative to patients allergic to $\beta$ lactam antibiotics because of its low cost, low side effects and good tissue penetration [11, 16, 24]. Steward et al. [21] have described different phenotypes which include $\mathrm{iMLS}_{\mathrm{B}}, \mathrm{CMLS}_{\mathrm{B}}$, moderate sensitive (MS) and sensitive (S) among Staphylococcal isolates resistant to macrolide. Macrolide resistant Staphylococcal isolates may have constitutive or inducible resistant to clindamycin which is difficult to detect in routine laboratory test if they are not placed adjacent to one another. During clindamycin therapy, these inducible phenotypes can gradually develop constitutively resistant mutants both in vitro and in vivo. Hence, detection of such resistant phenotypes is important to minimize treatment failure [7]. Since the $\mathrm{iMLS}_{\mathrm{B}}$ resistance mechanism is unrecognized by using standard susceptibility test methods and its prevalence varies according to geographic location, D-test becomes an imperative part of routine antimicrobial susceptibility test for all clinical isolates $[25,26]$.

In this study, almost all isolates of Staphylococci presented $\mathrm{MLS}_{\mathrm{B}}$ resistant phenotypes. In fact, $\mathrm{CMLS} \mathrm{B}_{\mathrm{B}}$ resistant phenotype was the most common and highest (40\%) followed by $\mathrm{MS}_{B}(37 \%)$ and $\mathrm{iMLS}_{\mathrm{B}}(23 \%)$ phenotypes. Varying prevalence rates of $M_{L} S_{B}$ resistance phenotype are reported by other studies $[15,17$, $27,28,29$ ]. iMLS ${ }_{B}$ was found higher $(44 \%)$ in MRSA whereas it was $\mathrm{CMLS}_{B}(36 \%)$ in MSSA. Among 21 CNS isolates, $\mathrm{iMLS}_{\mathrm{B}}, \mathrm{CMLS}_{\mathrm{B}}$ and MS phenotype was detected in $2(3.3 \%), 16(26.7 \%)$ and $3(5 \%)$ respectively. Constitutive resistance among CNS was observed in various studies as well $[20,29,30]$. $\mathrm{CMLS}_{\mathrm{B}}$ was detected among $80 \%$ MRCNS and $67 \%$ MSCNS while iMLS $\mathrm{B}_{\mathrm{B}}$ was observed only among MRCNS (13.3\%) and not in MSCNS. Variations in these results depend on factors like sample size, patient's age, geographical region, population studied, trends of antibiotic prescription, circulating clones and origin of isolates [31].

Studies on the prevalence of $\mathrm{MLS}_{\mathrm{B}}$ resistance in Staphylococci using phenotypic method is available to some extent but data on genetic determinants is limited in Nepal. Resistance to $\mathrm{MLS}_{\mathrm{B}}$ is mostly based on ribosomal target modification encoded by erm gene for enzyme methylase. The resistance mechanism is 
the methylation of $23 \mathrm{~S}$ binding site to cause premature dissociation of the peptidyl tRNA from the ribosome halting further protein synthesis. In inducible resistance, the bacteria produce inactive mRNA that is unable to encode methylase. The mRNA becomes active only in the presence of a macrolide inducer. By contrast, in constitutive expression, active methylase mRNA is produced even in the absence of an inducer. The strains harbouring an inducible erm gene are resistant to the inducer but remain susceptible to non inducer macrolides and lincosamides. Mutations in the promoter region of erm allow production of methylase without an inducer $[4,32]$.

According our findings, the ermC gene was the most prevalent among Staphylococci isolates $(22,37 \%)$ followed by ermB among $6(10 \%)$ isolates while ermA gene was not detected. The presence of erm genes varied in studies carried out by different researchers. The study carried out by Martineau et al. [33] in Canada, ermA gene was detected among $20.9 \%$ S. aureus and $66 \%$ CNS. Also, a multi-centre study in 24 European University hospitals, prevalence of ermA gene was higher than ermC and ermB genes among 851 S. aureus [19]. Lina et al. [29] showed $63.2 \%$ S. aureus positive for ermA gene and $44 \%$ CNS positive for ermC gene while ermB was positive only in $1 \%$ Staphylococci. As opposed to these studies, our study did not detect any ermA gene.

The strains with MS phenotype are resistant to macrolide and streptogramin but are susceptible to clindamycin. Such resistance is encoded by msr gene, either msrA or msrB [4]. Conferring active efflux of antibiotics such that intracellular concentration becomes low and ribosomes are free from the antibiotics. In this study, $6(10 \%)$ isolates were detected with the presence of msrA and $7(12 \%)$ with msrB genes. Export of macrolides is rarely seen in S. aureus but seems to be more frequent in CNS [29].

The erm genes were detected in 5 isolates showing $\mathrm{CMLS}_{B}, 12$ isolates showing $\mathrm{iMLS}_{\mathrm{B}}$ and 2 isolates with MS phenotype. Similarly, ermB gene was detected 3 isolates showing $\mathrm{CMLS}_{B}, 2$ isolates showing $\mathrm{iMLS}_{B}$ and a single isolate with MS phenotype. None of the isolates with $\mathrm{MLS}_{B}$ resistance were detected with ermA gene. This result is in accordance with the study carried out in Germany with $63 \% \mathrm{ermC}$ showing constitutive resistance [34]. In contrast to situations reported by other studies [11, 29], in which constitutive resistance tends to be caused by ermA and the inducible phenotype is caused by ermC.

None of the erythromycin resistant isolates were encountered without any of the tested resistant mechanism. This is in contrast to other previous studies where unidentified resistance mechanism were observed among Staphylococcal isolates [11, 20]. Additionally, resistant genes were not detected among phenotypically erythromycin susceptible isolates. Our findings show a correlation between the presence of specific genes or sets of genes and the phenotypic $\mathrm{MLS}_{\mathrm{B}}$ resistance.

\section{Conclusions}

Staphylococci are important human pathogen causing hospital and community acquired infection. These are resistant to commonly used antibiotics like methicillin generating methicillin resistant isolates. But clindamycin resistance in the form of iMLSB and CMLSB limits the therapeutic options for such 
methicillin resistant isolates. In this study, we tried detecting the presence of common resistant genes as erm and msr along with phenotypic method in clindamycin resistant clinical isolates. Constitutive and inducible $\mathrm{MLS}_{\mathrm{B}}$ phenotype was observed among $40 \%$ and $23 \%$ isolates respectively by $\mathrm{D}$ test. The most prevalent resistant gene was ermC gene (37\%) followed by msrB (12\%), ermB (10\%) and msrA (10\%). Therefore, these resistance mechanisms should be identified that will help us in guiding the clinicians regarding the judicious use of clindamycin.

\section{Abbreviations}

AST: Antibiotic susceptibility test

CD: Clindamycin

CLSI: Clinical and Laboratory Standard Institute

$\mathrm{CMLS}_{\mathrm{B}}$ : Constitutive Marolides, lincosamides and streptogramin B

CNS: Coagulase negative Staphylococci

E: Erythromycin

$\mathrm{iMLS}_{\mathrm{B}}$ : Inducible Marolides, lincosamides and streptogramin B

MHA: Mueller Hinton Agar

$\mathrm{MLS}_{\mathrm{B}}$ : Marolides, lincosamides and streptogramin B

MRCNS: Methicillin resistant coagulase negative Staphylococci

MRSA: Methicillin resistant Staphylococcus aureus

PCR: Polymerase Chain Reaction

R: Resistant

S: Sensitive

\section{Declarations}

\section{Ethical approval and consent to participate}

The clinical specimens used in this study were received for routine diagnostic process in the Clinical Microbiology Laboratory. As acquiring the samples and data's did not involve direct patient contact and did not interrupt routine clinical care, formal ethics approval was not necessary as comply with the 
guidelines of Nepal Health research Council. Permission to conduct the study was obtained from the IRC (Institutional Review Committee) of the hospital.

\section{Consent for publication}

Not applicable.

\section{Availability of data and materials}

The data sets analyzed during the current study is available from the corresponding author on reasonable request.

\section{Competing interests}

The authors declare that they have no competing interests.

\section{Acknowledgements}

We would like to thank B \& B hospital, Gwarko for allowing collection and processing of clinical samples and Interprid Nepal, Thapathali, Kathmandu for our molecular analysis.

\section{Funding}

No funding was obtained

\section{Authors' contributions}

DN and SM conceived the design of the study. SM and KP prepared the manuscript. DN, ANS and AG involved in processing the samples and data analysis. SM supervised the work and manuscript. All authors read and approved the final manuscript.

\section{References}

1. Casey AL, Lambert PA, Elliott TSJ. Staphylococci. Int J Antimicrob Agents. 2007; 29: (Suppl 3), S23S32.

2. Yilmaz G, Aydin K, Iskender S, Caylan R, Koksal I. Detection and prevalence of inducible clindamycin resistance in staphylococci. J Med Microbiol. 2007; 56: 342-345.

3. Appelbaum PC. Microbiology of antibiotic resistance in Staphylococcus aureus. Clin Infect Dis. 2007; 45: S165-S170.

4. Lecercq R. Mechanism of resistance to macrolides and lincosamides: nature of the resistance elements and their clinical implications. Clin Infect Dis. 2002; 34: 482-492.

5. Gadepalli R, Dhawan B, Mohanty S, Kapil A, Das BK, Chaudhry R. Inducible clindamycin resistance in clinical isolates of Staphylococcus aureus. Indian J Med Res. 2006; 123: 571-573. 
6. Gemmell C, Edwards D, Fraise A, Gould K, Ridgway GL, Warren RE. Guidelines for the prophylaxis and treatment of methicillin-resistant Staphylococcus aureus (MRSA) infections in the UK. J Antimicrob Chemother.2006; 57: 589-608.

7. Deotale V, Mendiratta DK, Raut U, Narang P. Inducible clindamycin resistance in Staphylococcus aureus isolated from clinical samples. Indian J Med Microbiol.2010; 28: 124-126.

8. Saderi H, Emadi B, Owlia P. Phenotypic and genotypic study of macrolide, lincosamide and streptogramin B $\left(\mathrm{MLS}_{\mathrm{B}}\right)$ resistance in clinical isolates of Staphylococcus aureus in Tehran, Iran. Med Sci Monit. 2011; 17: BR48-53.

9. Gherardi G, De Florio L, Lorino G, Fico L, Dicuonzo G. Macrolide resistance genotypes and phenotypes among erythromycin-resistant clinical isolates of Staphylococcus aureus and coagulasenegative staphylococci, Italy. FEMS Immunol Med Microbiol. 2009; 55: 62-67.

10. Juda M, Chudzik-Rzad B, Malm A. The prevalence of genotypes that determine resistance to macrolides, loncosamides, and streptogramin B compared with spiramycin susceptibility among erythromycin-resistant Staphylococcus epidermidis. Mem Inst Oswaldo Cruz. 2016; 111: 155-160.

11. Fiebelkorn KR, Crawford SA, McElmeel ML, Jorgensen JH. Practical disk diffusion method for detection of inducible clindamycin resistance in Staphylococcus aureus and coagulase-negative staphylococci. J Clin Microbiology. 2003; 41: 4740-4744.

12. Zelazny AM, Ferraro MJ, Glennen A, Hindler JF, Mann LM, Munro S, Murray PR, Reller LB, Tenover FC, Jorgensen $\mathrm{JH}$. Selection of strains for quality assessment of the disk induction method for detection of inducible clindamycin resistance in staphylococci: A CLSI collaborative study. J Clin Microbiol.2005; 43: 2613-2615.

13. Clinical and Laboratory Standards Institute (CLSI)Performance standards for antimicrobial susceptibility testing. 2015; CLSI document M100- S22. Clinical and Laboratory Standards Institute, Wayne, PA.

14. Cheesebrough M. District Laboratory Practice in Tropical Countries. Cambridge University Press. 2006; 143-157.

15. Ghanbari F, Ghajavand H, Havaei R, Jami M, Khademi F, Heydari L, Shahin M, Havaei SA. Distribution of erm genes among Staphylococcus aureus isolates with inducible resistance to clindamycin in Isfahan, Iran. Adv Biomed Res. 2016; 5:

16. Drinkovic D, Fuller ER, Shore KP, Holland DJ, Ellis-Pegler R. Clindamycin treatment of Staphylococcus aureus expressing inducible clindamycin resistance. J Antimicrob Chemother 2001; 48: 315-316.

17. Adhikari RP, Shrestha S, Barakoti A, Amatya R. Inducible clindamycin and methicillin resistant Staphylococcus aureus in a tertiary care hospital, Kathmandu, Nepal. BMC Infectious Diseases. 2017; 17: 483.

18. Thapa S, Sapkota LB. Prevalence of inducible clindamycin resistance in erythromycin resistant clinical isolates of Staphylococcus aureus and CONS at Tertiary care hospital. Journal of college of medical sciences-Nepal. 2016; 12: 83-88. 
19. Schmitz FJ, Sadurski R, Kray A, Boos M, Geisel R, Köhrer K, Verhoef J, Fluit AC. Prevalence of macrolide-resistance genes in Staphylococcus aureus and Enterococcus faecium isolates from 24 European university hospitals. J Antimicrob Chemother. 2000; 45: 891-894.

20. Schreckenberger PC, llendo E, Ristow KL. Incidence of constitutive and inducible clindamycin resistance in Staphylococcus aureus and coagulase-negative staphylococci in a community and a tertiary care hospital. J Clin Microbiol. 2004; 42: 2777-2779.

21. Steward CD, Raney PM, Morrell AK, Williams PP, McDougal LK, Jevitt L, McGowan JE, Tenover FC. Testing for induction of clindamycin resistance in erythromycin-resistant isolates of Staphylococcus aureus. J Clin Microbiol. 2005; 43: 1716-1721.

22. Rijal KR, Pahari N, Shrestha BK, Nepal AK, Paudel B, Mahato P, Skalko-Basnet N. Prevalence of methicillin resistant Staphylococcus aureus in school children of Pokhara. Nepal Med Coll J. 2008; 10: 192-195.

23. Tiwari HK, Das AK, Sapkota D, Sivrajan K, Pahwa VK. Methicillin resistant Staphylococcus aureus: prevalence and antibiogram in a tertiary care hospital in western Nepal. J Infect Dev Ctries. 2009; 3: 681-684.

24. Prabhu K, Rao S, Rao V. Inducible clindamycin resistance in Staphylococcus isolated from clinical samples. J Lab Physicians. 2011; 3: 25-27.

25. Lewis JS $2^{\text {nd }}$, Jorgensen $\mathrm{JH}$. Inducible clindamycin resistance in Staphylococci: Should clinicians and microbiologists be concerned? Clin Infect Dis. 2005; 40: 280-285.

26. O'Sullivan MV, Cai Y, Kong F, Zeng X, Gilbert GL. Influence of disk separation distance on accuracy of the disk approximation test for detection of inducible clindamycin resistance in Staphylococcus spp. J Clin Microbiol. 2006; 4: 4072-4076.

27. Ansari S, Nepal HP, Gautam R, Rayamajhi N, Shrestha S, Upadhyay G. Threat of drug resistant Staphylococcus aureus to health in Nepal. BMC Infectious Disease. 2014; 14: 157.

28. Sah P, Khanal R, Lamichhane P, Upadhaya S, Lamsal A, Pahwa VK Inducible and constitutive clindamycin resistance in Staphylococcus aureus: an experience from western Nepal. International Journal of Biomedical Research. 2015; 6: 316-319.

29. Lina G, Quaglia A, Reverdy ME, Leclercq R, Vandenesch F, Etienne J. Distribution of genes encoding resistance to macrolides, lincosamides, and streptogramins among staphylococci. Antimicrob Agents Chemother. 1999; 43: 1062-1066.

30. Hamilton-Miller JM, Shah S. Patterns of phenotypic resistance to the macrolide-lincosamideketolide-streptogramin group of antibiotics in staphylococci. J Antimicrob Chemother. 2000; 46: 941-949.

31. Atkas Z, Aridogan A, Kayacan CB, Aydin D. Resistance to macrolide, lincosamide and streptogramin antibiotics in Staphylococci isolated in Istanbul, Turkey. J Microbiol. 2007; 45: 286-290.

32. Weisblum B. Erythromycin resistance by ribosome modification. Antimicrob Agents Chemother. 1995; 39: 
33. Martineau F, Picard FJ, Lansac N, Menard C, Roy PH, Quellette M, Bergeron MG. Correlation between the resistance genotype determined by multiplex PCR assays and the antibiotic susceptibility patterns of Staphylococcus aureus and Staphylococcus epidermidis. Antimicrob Agents Chemother. 2000; 44: 231-238.

34. Gatermann SG, Koschinski T, Friedrich S. Distribution and expression of macrolide resistance genes in coagulase-negative staphylococci Clin Microbiol Infect. 2007;13: 777-781.

\section{Figures}

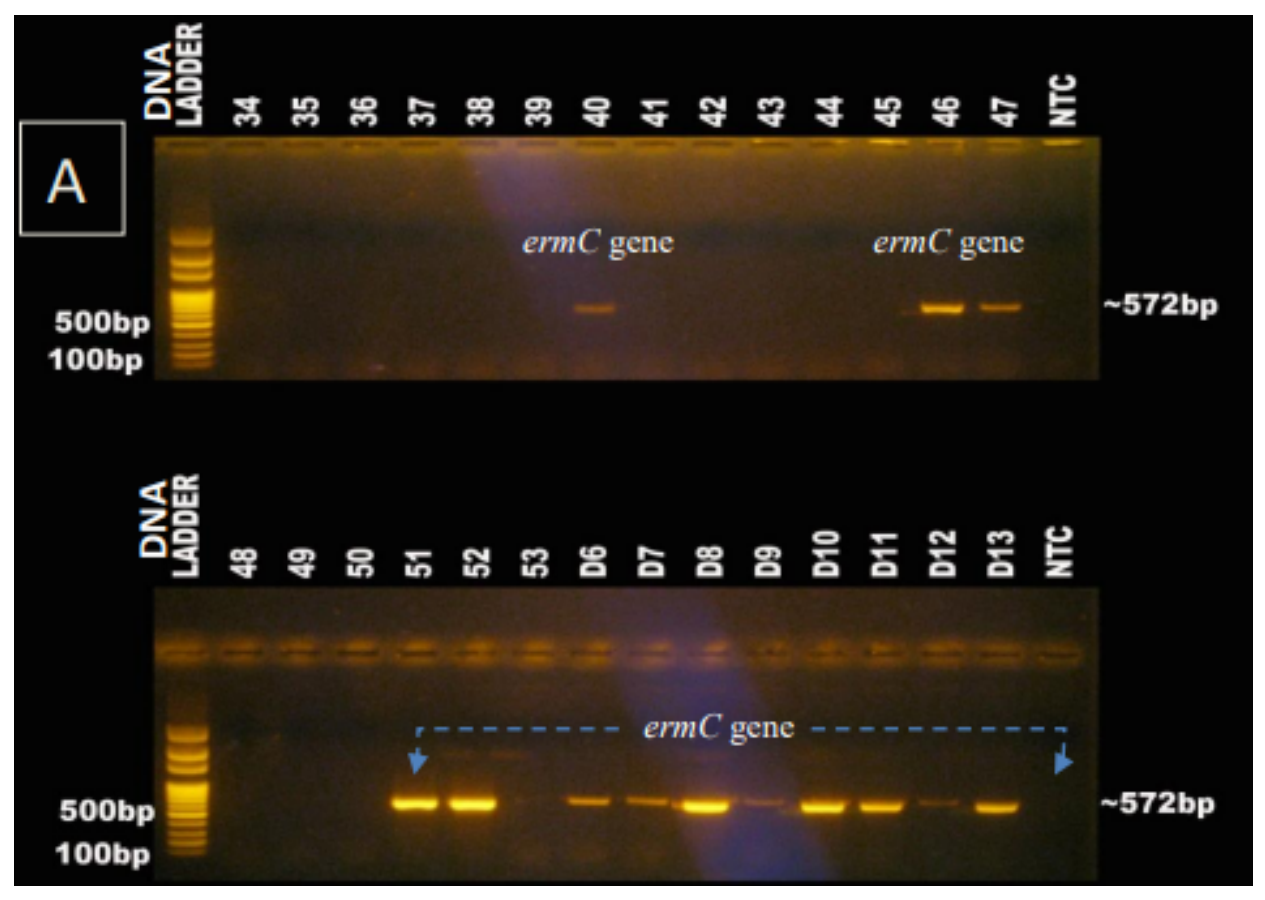

Figure 2

Occurrence of ermC gene in Staphylococcal isolates $34-53=$ Staphylococcal isolates; D6 - D13 = D test positive Staphylococcal isolates; NTC = Negative template control 


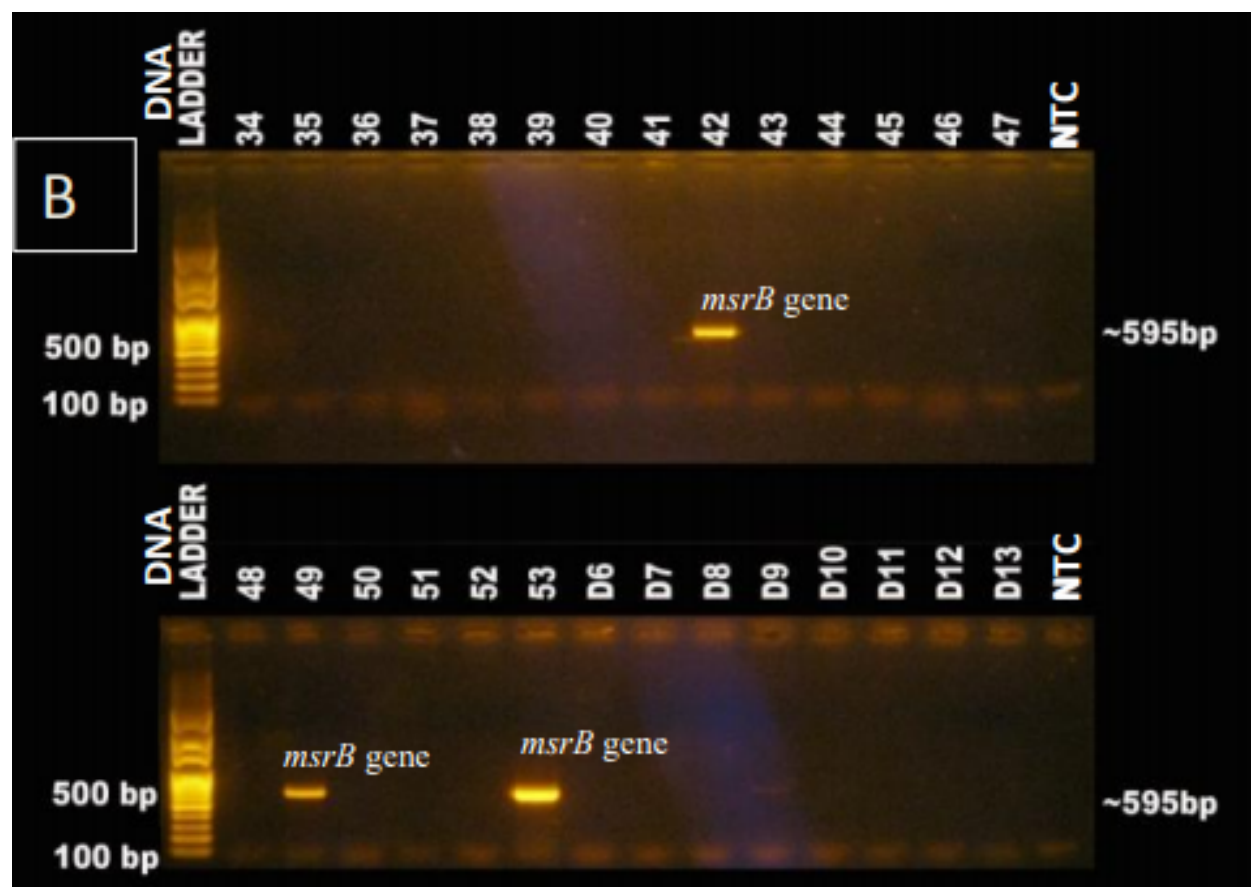

\section{Figure 4}

Occurrence of msrB gene in Staphylococcal isolates 34 - 53 = Staphylococcal isolates; D6 - D13 = D test positive Staphylococcal isolates; NTC $=$ Negative template control 